\title{
Teaching Research on the Course of "Post Processing of Film and TV" in Higher Vocational Colleges in the Process of Transformation
}

\author{
Jiang Chunxu ${ }^{1}$, a \\ ${ }^{1}$ Baicheng Normal College, Equipment Department, Baicheng, Jilin \\ ajiang-19880213@qq.com
}

Keywords: Vocational Education; Post Processing of Film and TV; Project Teaching

\begin{abstract}
Project teaching, the key to success lies in the guidance of teaching and student cooperation, both are indispensable. At the same time, the reform of teaching, not only to a single course to learn and master the core skills, should enable students to truly learn knowledge and skills and apply their knowledge. The "video post processing" course project driven by the project process oriented project teaching, let the students to form a team and directly involved in the project, to stimulate students' learning enthusiasm and potential, to cultivate students' comprehensive ability of occupation.
\end{abstract}

\section{Introduction}

"Film and television post-processing" is a vocational college radio and television director and other professional core professional courses, is a strong practical course. The course is designed to develop students' practical hands-on skills, so that students master the basic skills of film and television post-production, to the film independent of the clip and the production of late effects. Film and television post-production for film and television works is essential, and post-processing this part of the film is usually easy to be ignored, so I seriously read some of the late film and television production and combined with their own past on the film and television production experience, A set of post - production teaching methods.

\section{The Overall Structure of the "Post -Processing" Course}

According to the characteristics of this course, students are required to master three aspects in this course:

Learn to learn later software. Students are required to explain the software in the course of the course, the students can carry out in-depth study in order to cultivate students' self-learning ability. The first part of the video after the completion of the work is to screen and video clips. Usually a two hour film, early video shoot length will reach more than six hours, some even more, video post production personnel after getting the original video to preliminary screening and editing of the video.

Learn to organize projects. This course is to finally complete the Assessment Series in the form of operation, for the title, he not only just application technology, one part is the largest per planning stage, this stage includes topics, Lens script writing etc.. We in some movies usually see some characters of deformation, collapse, high-rise buildings in the city a huge explosion in reality simply not possible scenes, these scenes show the post-processing effects are dependent on the film. The late effects of the film processing can effectively increase the shock effect of the film and the performance of these special effects in the production of movies or TV plays a very wide range of applications.

Learn to complete projects independently. Requires a person to complete a work independently within the prescribed time.In the later period of the film and television works, it is usually necessary to dub the video and add subtitles. These video post production methods greatly enrich the content of the video, effectively enhance the audience's viewing effect.

In teaching methods, to guide students to think independently, to answer questions from the students, to guide students to find problems and rules, and guide students to use the manual 
materials for self-study, to cultivate students' observation ability, analysis ability and planning ability. Then the specific curriculum design in the following four stages of teaching:

The first stage: through a simple case of production to allow students to master the basic operation of the software.The teaching strategy is "case study, practice and training", which allows students to master the basic knowledge and basic methods of operation. Next introduced around the case, synchronous teach on theoretical knowledge, the students are in class and follow the teacher demonstrates synchronous imitation exercises, listening, and practice to enable students to acquire knowledge and skills imperceptibly.

The second stage: the cultivation of students' independent thinking ability.After mastering the basic operation method of PR in the student, we will strengthen students understanding of video post-processing through imitation and analysis of the case, the focus of teaching into training students' ability of observation, image thinking ability and analysis ability.

The third stage: the development of organizational planning ability. The purpose of learning knowledge lies not only in the simple imitation, but also in the application and creation. At this stage is mainly to see the students in a project process control ability, from project planning to storyboard draft presentation, and then to the final product, which exists much difference can reflect the students' ability of planning at the beginning and his foresight.

The fourth stage: the cultivation of expression ability.Teachers guide students to evaluate and reflect on their own and others' tasks. Through the presentation of the work, students learn from each other, learn from each other.

\section{The project teaching design of "post processing of film and TV"}

The course of "post processing of film and TV" emphasizes practice and operation, and the use of traditional teaching methods will lead to the lack of theoretical depth, lack of practical ability and so on. In addition, the higher vocational college students have a preference for skill learning and lack of initiative in learning, which is more suitable for Higher Vocational education.

Design ideas.The course will be in accordance with the project design, project design is no longer confined to the course itself, but the course "photography", "nonlinear editing and post production" curriculum related knowledge and skills into the curriculum project teaching, from the early story-boarding, captured the late movie clips, special effect, so that the students can mastery of the course and course, to obtain a more complete knowledge transfer.

Project structure.This course is divided into two parts: the overall project and the project. The whole project is to build a complete video production and the creation of film and television works as the main content, through the implementation of the overall project, improve the students' creativity, teamwork ability, practical ability etc.. Students in the overall project, in the main position, and teachers, the main role in the overall project, is the supervision, guidance, evaluation. The project is mainly aimed at the specific knowledge and skills in this course, focusing on the students' learning of specific knowledge and skills. In the sub project, the teacher is in the leading position, carries on the necessary demonstration operation, guides the student and solves the student doubt. Project evaluation system.The assessment of the course is mainly based on the ability evaluation, mainly to evaluate the effect of the whole project, and to assist the evaluation of the project. The course is examined in a manner of examination.

The overall project includes two aspects of evaluation, one is the overall evaluation of the project team, the two is the evaluation of the project team members. Evaluation of the project group as a whole, on the basis of the overall project completion and completion effect to teacher evaluation; evaluation of the project team members, team members were evaluated according to contribution, team evaluation, teacher evaluation supplement.

Usually before the film, the director has already established the theme of the film and the idea of the film. The director will last long film than the original video more to post production personnel, the original video is usually not as compact film the final presentation, but is relatively messy. Therefore, the film post production personnel need to find those who can effectively reflect the theme of the film and thought in director provided the original video screen, then these images 
effectively together, visually presented to the audience.

In the process of video clips in the video is the need to pay particular attention to the continuity and integrity of the original video, messy by post delete a lot of unrelated scenes and dialogue, will usually destroy the story of the film. Therefore, the post production of film and television is equivalent to a re creation of the process, the production staff need to find the sensitive points of the different scenes and make the film look coherent, complete and not appear abrupt.

\section{The Requirements "Post Processing of Film and TV"Course}

Although the film and television works need complex post-processing, sometimes also use a large number of special effects to achieve the specific effect of the film. However, in the process of film and television works in the process of the need to respect some of the objective reality of the law, or some of the exaggerated effects of the film will be a serious misleading audience, resulting in bad influence.

In any case, the film and television works should be as a work of art, since it is a work of art, it should have its own unique charm and demeanor. The production of film and television works in the late stage should resist the shoddy, vulgar and rude things, can not make the film and television works to give people a negative, vulgar things.

With the continuous progress of society, people's awareness and appreciation of the level is also rising, which also put forward new requirements for the post production of film and television works. Post production of film and television work level not only should keep pace with the times and continue to move forward, the film and television works also have their own unique mission is to lead people's thinking and understanding of height and culture, film and television works should represent an era of art.

Post-processing of Film and television requires very professional technology, technology is the guarantee of all ideas and performance. There are ideas and plans, but the technology is not up to the requirements of the operation is very empty. In the process of teaching in general for students basic video clip and special technical requirements need teachers strictly, this is the basic quality requirements of a post production personnel, this is also the film post production to reach the first level.

Usually show excellent works by well-known artists to the students in the classroom, these works may not be a video but a masterpiece or a classic photo, students through the great works of art appreciation can be gradually developed for art appreciation, and finally to slowly cultivate their artistic realm.

If we say that the post processing of the film and television workers only need superb video production technology and unique artistic accomplishment to complete the director's grasp of the work, which is obviously superficial. The micro video producers have reason to reflect the producers own thoughts in the works, movie producers are not a movie production tool, but as an independent person, so in does not violate the request of the Director under the condition of appropriate in the film reflects the production the value of their own is very necessary.

\section{Discussion and Application of Teaching Methods}

Attach importance to the introduction of theoretical knowledge.The first is the concept of post processing film and television, the late stage of the film and television is a combination of various elements of the film and television works, including screen editing, recording lines, the preparation of music sound, synthetic effects, etc.. The post processing of film and television refers to the process of realizing special visual effect with the help of computer hardware and digital processing technology. The second is the comprehensive application of film theory, such as light, motion, composition, color, size, angle and other elements of the six, achieve the effect of different conditions, can use the basic understanding of the six elements.

Goal driven, cultivate students' active learning habits.The film and television post-processing course is a course with strong application, the ultimate goal of teaching is to enable students to use 
the corresponding software PR to complete their own project design and production. Usually in the actual teaching, the class arrangement is scattered, the teaching task is generally based on knowledge points, so through the book on the production of some cases can learn basic knowledge, but can not let the students master all the functions. In the process of teaching, the teacher should integrate the key frame, the drawing image and so on into one task. For example, when the key frame animation, set up a target for the students, such as the production of small butterflies flying. By completing this task, students will be able to grasp the basic operation of the key frames and related knowledge points to achieve the purpose of task driven learning.

When setting a target task, the students will have the purpose and initiative to seek the relevant knowledge to solve the problem. On the one hand, the students' learning enthusiasm is improved, on the other hand, the learning efficiency is improved obviously. Goal driven tasks are generally applicable to the introduction of curriculum teaching and the use of small synthesis.

\section{Conclusion}

The project oriented teaching of the course focuses on the implementation of the project teaching in the course of the actual operation also encountered the following problems:

Students have a direct impact on the teaching effectiveness of the per course related skills. This course is not an independent course with a single skill, and it is closely related to the previous curriculum. In order to carry out the project teaching smoothly, it is necessary for the students to reach the very proficient level of the related skills of the early curriculum, and then to complete the whole project. Otherwise, as long as the shooting script, filming the movie clips, in any link will appear Canton phenomenon caused by students' weariness, affect the normal projects, resulting in the project ran aground.

The implementation of the overall project, so that the acquisition of knowledge and skills and the acquisition of quality skills there is a certain contradiction. Students according to their own preferences or is based on the difficult degree of duty selected for their roles, role nature and emphasis of each person is different, will cause the students do not get full exercise at the same time, students may because the task is heavy and tired, boycott mood. Therefore, in the process of project teaching, how to rationalize the degree, but also need long-term exploration and experience accumulation.

Video post processing course is a course with strong practice, in the teaching should not only cultivate students' understanding of the theory of cognitive ability, enable students to use the knowledge of the actual production projects, so as to be able to engage in related work. I believe that as long as teachers can fully interpret the "theory of knowledge analysis, task driven, case oriented, project driven" the Quartet, will enable students to learn a good video post processing course, operation ability has been a qualitative leap, to cultivate society needed talent and practical skills of high occupation workers, so that our teaching has become gorgeous music.

The shortcomings of "Post Processing of Film and TV"course hope to improve in the future.

\section{References}

[1] Fu Ruoqing, Chen Fei, Xu Jia.Post Production of Film and Television in the Digital Age [J].Modern Film Technology, 2009 (04);

[2] Zhang Yunxiang, He Yunpeng.Talk about Post Production and Editing Field [J]. Heilongjiang Science and Technology Letter,2013(16);

[3] Dong Qianwen. On Post Production and Processing of Film and Television Works[J].Popular Literature and Art, 2012 (11);

[4] Huang Xiukun. On Television Post Production Needs to Pay Attention to Matters[J].Brilliant Work, 2013 (19);

[5] Fan Fangchen. Application Research in the Visual Arts in Film and Television Post Production[J].Popular Literature and Art, 2013 (02);

[6] Qiang Bin.The Application of Special Effects Software in the Post Production of TV[J].Guangdong Technology, 2010 (19). 